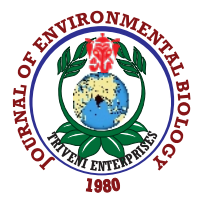

\title{
Amelioration potential of Withania sonmifera root extract on hexavalent chromium induced micronucleus in Channa punctatus (Bloch, 1793)
}

\section{S.P. Trivedi*, R. Prasad and A.A. Khan}

Department of Zoology, Environmental Toxicology \& Bioremediation Laboratory, University of Lucknow, Lucknow- 226 007, India

*Corresponding Author Email : sat060523@gmail.com

\section{Abstract}

Aim: This study aimed to infer the ameliorative potential of Withania somnifera ('Ashwagandha') against hexavalent chromium induced micronuclei in Channa punctatus.

Methodology: After laboratory acclimatization of 15 days, C. punctatus $(12.20 \mathrm{~cm}, 42 \mathrm{~g})$ were maintained in six groups. Group I, served as control. Fishes of groups II and III were separately exposed to root extract of $W$. somnifera $\left(3 \mathrm{mg}^{-1}\right)$ and $96 \mathrm{hr}-\mathrm{LC}_{50} / 10$ of $\mathrm{Cr}(\mathrm{VI}), 7.89 \mathrm{mg} \mathrm{l}^{-1}$, respectively, for $24,48,72$ and $96 \mathrm{hr}$. Contrarily, the fish of groups IV, $\mathrm{V}$ and $\mathrm{VI}$ were exposed to $7.89 \mathrm{mg} \mathrm{I}^{-1}$ of $\mathrm{Cr}(\mathrm{VI})$ along with increasing concentrations of root extract of $W$. somnifera $(1$, 2, $3 \mathrm{mg} \mathrm{I}^{-1}$ ), respectively. Induction of micronuclei was assessed in fishes of all the six groups after stipulated exposure periods.

Results: A significant induction $(p<0.05)$ in micronuclei frequency was observed in Group-III as compared to the control. On contrary, there was a significant $(p<0.05)$ decrease in frequency of micronuclei induction with increasing concentrations of root extract of $W$. somnifera, as compared to Group-III, after stipulated exposure periods in a dose and time-dependent manner.

Interpretation: Preliminary investigations

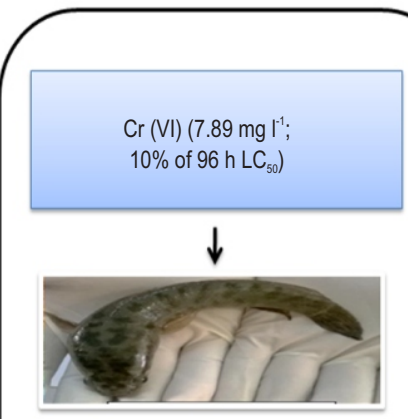
evinced that the root extract of $W$. somnifera has enough ameliorative potential against short term sub-lethal exposure to $\mathrm{Cr}(\mathrm{VI})$ induced genomic instability, i.e., micronuclei induction in $\mathrm{C}$. punctatus.

Key words: Channa punctatus, Chromium trioxide, Genotoxicity, Micronucleus, Withania somnifera

How to cite : Trivedi, S.P., R. Prasad and A.A. Khan: Amelioration potential of Withania sonmifera root extract on hexavalent chromium induced micronucleus in Channa punctatus (Bloch, 1793). J. Environ. Biol., 41, 672-679 (2020). 


\section{Introduction}

Hexavalent chromium, prevalent due to the anthropogenic activities, is a toxic industrial pollutant that possesses mutagenic and teratogenic properties. On contrary, occurrence of $\mathrm{Cr}$ (III) is mostly due to the natural activities. However, there have been a spurt in naturally occurring $\mathrm{Cr}(\mathrm{VI})$ in ground and surface waters at values surpassing the limits of $50 \mu \mathrm{g}$ $I^{-1}$ as prescribed by World Health Organization (2008). Hexavalent chromium, a known pollutant in aquatic habitats, got prominence due to its mutagenic abilities. It has been classified as Group 1 carcinogen by International Agency for Research on Cancer owing to its established carcinogenic effect (Banerjee et al., 2017). Blatant use of hexavalent chromium in tanning, paints, varnishes, electroplating, wood processing, dyes, paper making and mining industries has resulted in its accumulation to toxic levels that adversely affect both flora and fauna (Gu et al., 2015).

Chromium, the seventh most abundant element on earth has earned notoriety due to its variable oxidation states (Fendorf, 1995). In nature, $\mathrm{Cr}$ (III) and $\mathrm{Cr}$ (VI) found in abundant states are capable of harming animals, humans and plants as well (Mohanty and Patra, 2013). $\mathrm{Cr}$ (III) is not as efficient as $\mathrm{Cr}(\mathrm{VI})$ in entering the body of the organism as former is insoluble whereas the latter one is soluble in water making it dangerous (Gürkan et al., 2017; Wolińska et al., 2013). Chromium, particularly hexavalent chromium (Zayed and Terry, 2003) finds its way into the water bodies and becomes a threat for aquatic species (Ghani, 2011). India occupies third place in the world in chromite production followed by South Africa and Kazakhstan (Koleli and Demir, 2016). $\mathrm{Cr}(\mathrm{VI})$ has also been placed at $17^{\text {th }}$ position by the Agency for Toxic Substances and Disease Registry in its Substance Priority List (ATSDR, 2017). The U.S. Environmental Protection Agency (2018) has recommended $100 \mathrm{\mu gl}^{-1}$ of chromium consumption in all forms, as safe in drinking water. It has been documented that even at very low concentrations chromium is not only cytotoxic but also carcinogenic and mutagenic in nature (Hanaa et al., 2000). Cr (VI) may react with biological reductants like thiols and ascorbate to give rise to different reactive oxygen species (ROS) like superoxide ions $\left(\mathrm{O}_{2}^{-}\right)$, hydrogen peroxide $\left(\mathrm{H}_{2} \mathrm{O}_{2}\right)$ molecules and hydroxyl radicals $(\mathrm{OH}-)$ that lead to oxidative stress in the cells (Stohs and Bagchi, 1995).

Under oxidative stress, $\mathrm{H}_{2} \mathrm{O}_{2}$ is transported into the nucleus and directly damages the genomic DNA. Oxidative stress mediated DNA damage and oxidation of proteins and lipid peroxidation have been documented to implicate in carcinogenesis (Trachootham et al., 2009), neurodegeneration (Andersen, 2004; Shukla et al., 2011), atherosclerosis, diabetes (Paravicini and Touyz, 2006) and aging (Haigis and Yankner, 2010). $\mathrm{Cr}(\mathrm{VI})$, capable of damaging different cellular molecules due to its ability to produce reactive oxygen species (Feng et al., 2017), leads to molecular damages like DNA double-stranded breaks (DSBs) with greater micronuclei induction in blood cells of fish (Yadav and Trivedi, 2009a). Access of $\mathrm{Cr}$ (VI) to human beings through water-fish-human- continuum cannot be ruled out. Further, presence of $\mathrm{Cr}(\mathrm{VI})$ in aquatic habitats is liable to influence fish metabolism after its absorption through their gills, skin and gastro-intestinal tract. This adversely affects fish survival.

Thus, to safeguard fish biodiversity and productivity suitable measures to mitigate $\mathrm{Cr}(\mathrm{VI})$ contamination is the need of the hour. Conventional methods are energy intensive and cost expensive (Ohtake and Silver, 1994). The use of chromate reducing bacterial strains is although effective but has limited scope. For aquaculture purposes, where larger water bodies are involved, dietary inclusion (nutrigenomic approach) of plant metabolites, after preliminary biological screening of their therapeutic potential in laboratory microcosm seems to be an appropriate solution (Prasad and Trivedi, 2018). Ample studies emphasize biological screening of plant metabolites for their therapeutic/ameliorative potential against water borne toxicants in fishes (Sevgiler et al., 2011; Kumar and Trivedi, 2015; Dwivedi et al., 2015; Tiwari et al., 2016; Tiwari et al., 2017; Tiwari et al., 2019; Prasad et al., 2017). Withania somnifera (Solanaceae), vernacularly known as 'Ashwagandha' possesses enough therapeutic potential. Therapeutically significant metabolites, viz., alkaloids, steroidal flavonoids, saponins, lactones, withanolides, sitoindosides, and tannins etc., have already been identified, extracted and isolated from ashwagandha (Kapoor, 2001; Atta-ur-rahman et al., 1991; Bandyopadhyay et al., 2007; Mirjalili et al., 2009). Different parts of $W$. somnifera have been found with varied medicinal applications viz., anti-inflammatory, anti-oxidative, anticancer, anti-stress and immune-modulator, adaptogenic, besides being promoters for central nervous system, endocrine and cardiovascular activities (Alam et al., 2011). W. somnifera also has the ability to decrease oxidative stress as it decreases lipid peroxidation (Ahmad et al., 2010) and protein carbonyl content (Datta et al., 2011).

Thus, eco-toxicological manifestations in fishes can be effectively employed to find out early responses against environmental toxicants and, therefore, can also be adequately applied for routine environmental monitoring programs. Every Environmental Management Plan (EMP) emphasizes for routine bio-monitoring of aquatic regimes contaminated with noxious xenobiotics. Cytotoxic end markers, viz., Chromosomal Aberration Test and Micronucleus Assay etc., are preferred tools to monitor the extent of genotoxicity among aquatic animals. For assessing mutagenic, aneugenic and clastogenic effects of toxicants, the micronucleus assay can be relevant for both in-vitro and in-vivo studies (Bolognesi and Hayashi, 2011). Interestingly, the assay can be used in different target cells and tissues (Fenech et al., 2011; Laingam et al., 2008). Micronucleus assay is an important tool for uncovering the genotoxicity of an array of compounds, including nanoparticles. It has now become a preferred method for quantifying chromosome breakage, impaired DNA repair, chromosome loss, non-disjunction, necrosis, apoptosis and cytostasis (Fenech, 2007). Further, the Micronucleus assay is easy to score giving it an edge over other 
cytogenetic tests such as sister chromatid exchanges and chromosomal abstraction test. Keeping above mentioned facts into consideration, the present study was conducted to explore the ameliorative potential of $W$. somnifera root extract against water borne hexavalent chromium induced genomic instability in C. punctatus in terms of Micronucleus induction.

\section{Materials and Methods}

Fish and fish maintenance: Live and apparently healthy specimens of freshwater murrel, C. punctatus $(12.20 \pm 1.29 \mathrm{~cm}$, $42 \pm 2.01 \mathrm{~g}$ ) were procured from the local freshwater habitats around Lucknow (U.P.) and brought to the laboratory in plastic buckets and subjected to dip treatment of $0.05 \%$ potassium permanganate $\left(\mathrm{KMnO}_{4}\right)$ for 2 min to avoid any external dermal infection. Fish were washed repeatedly and transferred to a glass aquarium $\left(100 \times 40 \times 40 \mathrm{~cm}^{3}\right)$ and acclimatized for 15 days under laboratory conditions in $100 \mathrm{I}$ glass aquarium having $40 \mathrm{I}$ of $10 \mathrm{~d}$ (days) aged tap water is used for acclimatization of fish according to APHA, 2012. They were fed with pellets of commercial fish food, 'OPTIMUM', Bangsaothong, Thailand at fixed time intervals. In this study, the selection of exposure concentrations was based on $96 \mathrm{hr}-\mathrm{LC}_{50}$ value and No Observed Effect Concentration (NOEC) for $\mathrm{Cr}(\mathrm{VI})$ and Withania somnifera, respectively (Hutchinson et al., 2009).

Preparation of plant extract : The plant extract was prepared by weighing $25 \mathrm{~g}$ of root powder (Batch No. 0068, Jamna Herbal Research Ltd., Mandideep, Madhya Pradesh) of W. somnifera and wrapped in a thimble made of strong filter paper. Four thimbles (100 g) soaked in $250 \mathrm{ml}$ of $50 \%$ ethanol was extracted with the help of Soxhlet apparatus for $72 \mathrm{hr}$. The extract was further filtered, concentrated on rotavapor (Zhengzhou Great Wall, R-1050); dried in lyophilizer (Labconco, USA) under low pressure.

Experimental Design: C. punctatus being a bottom feeder has greater chances of accumulating higher concentration of metallic toxicants (Kumar et al., 2019). Fishes were subjected to short term static bioassays where they were exposed to sub-lethal concentration of $\mathrm{Cr}(\mathrm{VI})\left(96 \mathrm{hr}-\mathrm{LC}_{50} / 10\right)$ separately and simultaneously with varying concentrations of ethanolic root extract of W. somnifera. A 72 well-acclimatized fish were divided into 6 groups; each containing 12 specimens. Group-I served as a control (without any treatment), fish of group-II were given ethanolic extract of $W$. somnifera root powder $\left(3 \mathrm{mg} \mathrm{l}^{-1}\right)$ and that of group-III were subjected to chromium trioxide $\left(96 \mathrm{hr}-\mathrm{LC}_{50} / 10\right)$. Fish of groups IV, V and $\mathrm{VI}$ were subjected to chromium trioxide $\left(7.89 \mathrm{mg} \mathrm{I}^{-1}\right)$ along with increasing concentrations, of $W$. somnifera root extract (1,2 and 3 $\mathrm{mg} \mathrm{l}^{-1}$ ). After termination of stipulated exposure period, 24, 48, 72 and $96 \mathrm{hr}$, three fish (for reproducibility of the results) from each treated group along with control were anaesthetized with $0.1 \%$ diethyl ether. Blood samples were collected from their caudal vein by using a heparinized syringe and stored in Ethylendiaminetetraaceticacid coated vials for estimation of micronucleus.
Micronucleus (MN) Assay: Micronuclei, induced by multiple molecular mechanisms, are potential biomarkers of genotoxicity, applicable in both in-vitro and in-vivo systems (Fenech et al., 2011). Further, the MN assay, capable of detecting both aneugenic and clastogenic defects, is highly sensitive and simple in scoring, widely applicable in different cell types. It is internationally validated, and has potential for automation (Kirsch-Volders et al., 2011). The blood samples of fish from each groups were smeared on the slides. After overnight drying of slides at room temperature in a dust-free environment, they were fixed in methanol for $5 \mathrm{~min}$ and stained with MayGrunnwald's solution I and II sequentially for 3 and $5 \mathrm{~min}$; washed with distilled water and dried. Finally, slides were stained with $5 \%$ Giemsa (Sigma Aldrich, the USA) in phosphate buffer ( $\mathrm{pH} \mathrm{6.8)}$ for $30 \mathrm{~min}$ and subsequently washed for removing all the unbounded Giemsa stain. The slides were mounted with DPX (a mixture of distyrene, plasticizer and xylene) for microscopic examination (Schmid, 1975) using an oil immersion microscope (Nikon Corporation, K-12432). Approximately, 2000 erythrocytes with well-defined cytoplasm on each slide were scored for the presence of MN (Fenech et al., 2011). Micronucleus frequency was calculated by the following formula (Fenech, 2000):

$$
\mathrm{MN} \%=\frac{(\text { Number of cells containing micronuclei } \times 100)}{(\text { Total number of cells counted })}
$$

Statistical Analyses: Each treatment was performed with three replicates and the results were represented as mean \pm S.E. Statistical analyses were performed with the help of SPSS (Version-20.0) software. For the calculation of significance, one-way analysis of variance (ANOVA) with Tukey's post-hoc test was applied to test the significance $(p<0.05)$ of each result in fish erythrocytes.

\section{Results and Discussion}

The status of genomic instability was observed in terms of induction of MN frequency in erythrocytes of fish, C. punctatus. After exposure to sub-lethal test concentrations of $\mathrm{Cr}$-trioxide (96 $\mathrm{hr}-\mathrm{LC}_{50} / 10 ; 7.89 \mathrm{mg} \mathrm{l}^{-1}$ ) MN induction was found in an increasing trend with a steep increase at an interval of 24 and $48 \mathrm{hr}$ of exposure period (Fig. 1). In comparison to control, the frequency of micronuclei induction was significantly $(p<0.05)$ increased in Group-III with an increasing fold change of $2.12<4.40<5.16<$ 5.34 after 24, 48, 72 and $96 \mathrm{hr}$ respectively. The highest fold change of 5.34 was observed after $96 \mathrm{hr}$ of exposure period. Interestingly, there was a reduction in the frequency of micronuclei induction in groups- IV, V and VI exposed to $96 \mathrm{hr}$ $\mathrm{LC}_{50} / 10$ of $\mathrm{Cr}(\mathrm{VI})$ along with increasing concentrations (1, 2 and 3 $\left.\mathrm{mg} \mathrm{l}^{-1}\right)$ of $W$. somnifera root extract, after $24,48,72$ and $96 \mathrm{hr}$ of exposure periods; the highest reduction in the frequency of MN induction was observed after $96 \mathrm{hr}$ of exposure period in group $\mathrm{VI}$, as evident by a fold change of 3.97. After $24 \mathrm{hr}$ of exposure period, in groups IV, V, and VI, the fold changes of MN induction were 


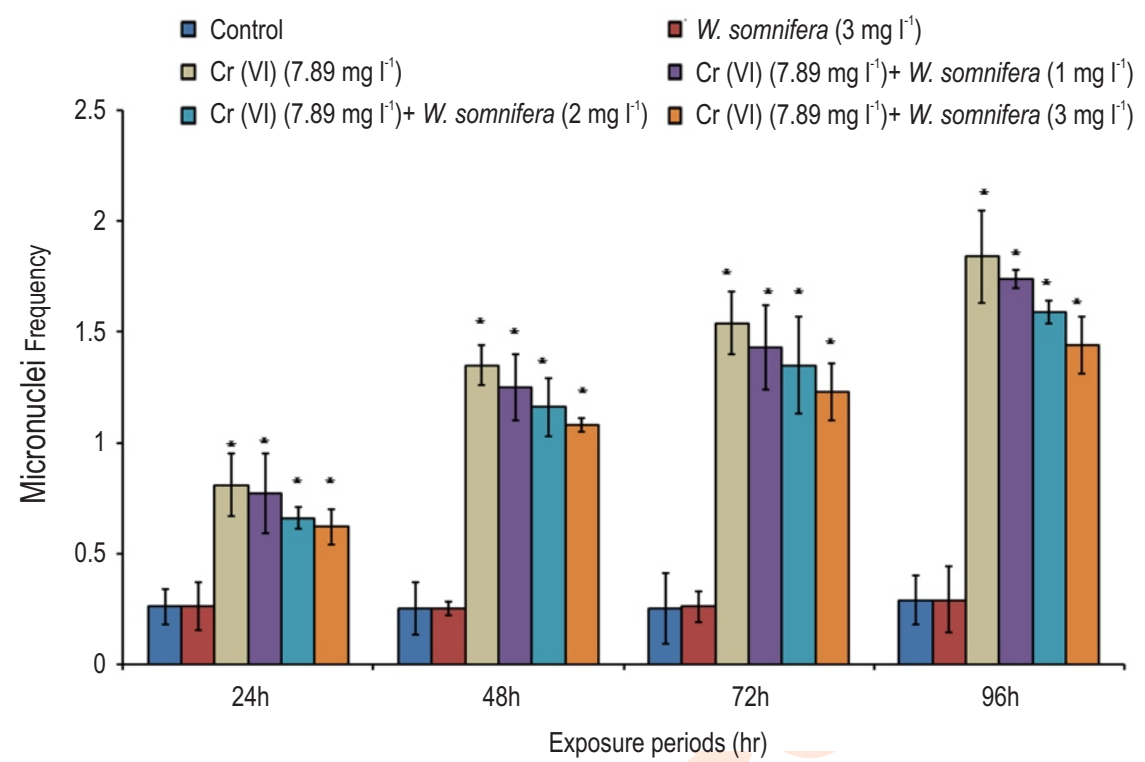

Fig. 1: Variations in induction of micronuclei frequencies in erythrocytes of Channa punctatus at different exposure periods. ("represent the significant values $(p<0.05)$. Values are expressed as mean \pm S.E.

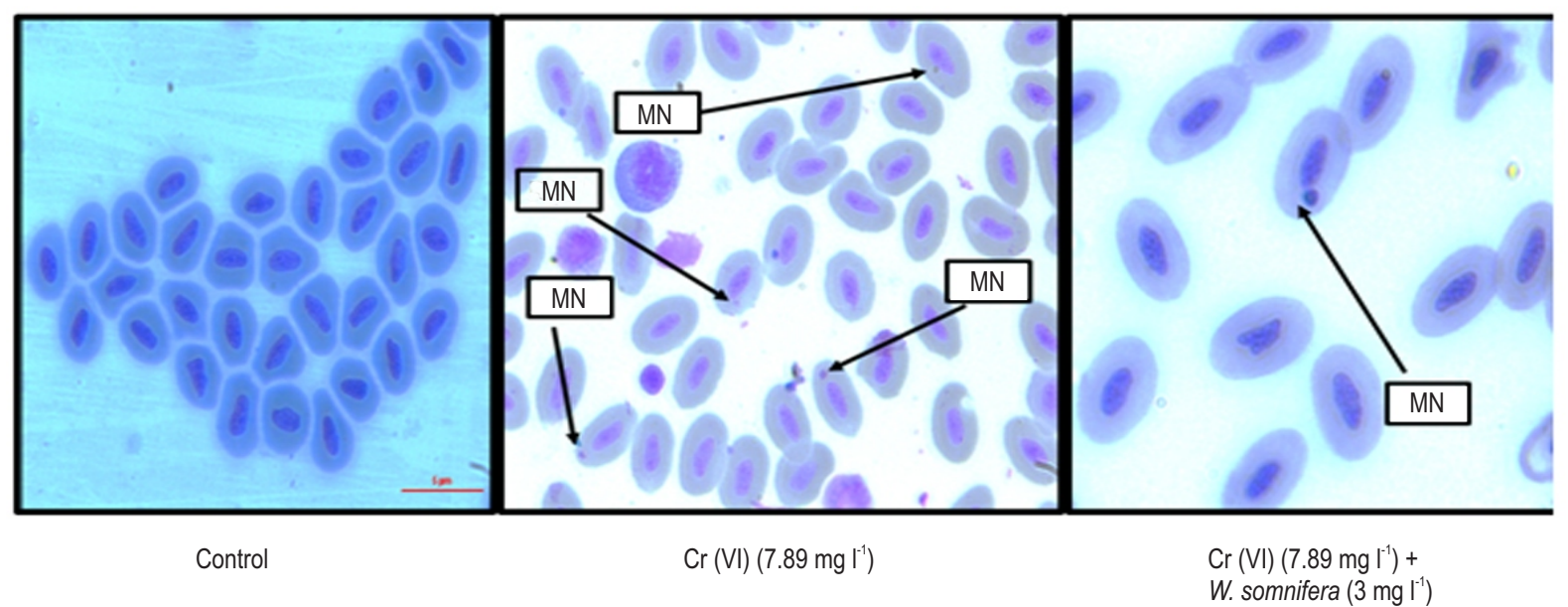

Fig. 2: Representative images showing $\mathrm{Cr}(\mathrm{VI})$ induced micronuclei $(\mathrm{B})$ and decreased micronuclei induction after exposure to $\mathrm{W}$. somnifera root extracts as compared to control $(A)$ in erythrocytes of $C$. punctatus.

recorded in the following decreasing order: $1.96>1.54>1.38$ in comparison to group III (2.12) with respect to control. Further, a declining trend was again recorded in frequency of MN induction in terms of observed fold changes $4.00>3.64>3.32$ after $48 \mathrm{hr}$ of exposure period, in groups IV, V and VI in comparison to group III (4.40) with respect to control. After $72 \mathrm{hr}$, a declining trend in the fold changes of MN induction in groups IV, $\mathrm{V}$ and $\mathrm{VI}$ were observed to be as $4.72>4.40>3.92$, when fold changes in MN was recorded as 5.16 with respect to control (Table. 1). Microphotographs showed higher formation of micronuclei in group III as compared to control and significant reduction in group
VI simultaneously exposed to $3 \mathrm{mg} \mathrm{I}^{-1}$ of $W$. somnifera root extract and $7.89 \mathrm{mgl}^{-1}$ of $\mathrm{Cr}$ (VI) (Fig.2).

A similar decreasing trend in fold changes of $\mathrm{MN}$ induction was also observed after $96 \mathrm{hr}$ of exposure in groups IV, $\mathrm{V}$ and $\mathrm{VI}(5.00>4.48>3.97)$, in comparison to group III (5.34), with respect to control. These observations suggestive of the fact that a fold change difference of 1.37 between group-III and groupVI exists, depicting a decrement in the frequency of MN induction after $96 \mathrm{hr}$ of exposure, wherein fish are simultaneously exposed with sub-lethal fraction of $\mathrm{Cr}(\mathrm{VI})\left(7.89 \mathrm{mg} \mathrm{I}^{-1}\right)$ and root extract of $W$. 
Table 1: Relative fold change in micronuclei induction in different exposure periods

\begin{tabular}{|c|c|c|c|c|c|}
\hline \multirow[t]{2}{*}{ MN induction } & \multirow[t]{2}{*}{ Exposure groups } & \multicolumn{4}{|c|}{ Exposure period (hr) } \\
\hline & & 24 & 48 & 72 & 96 \\
\hline & Group-I (Control) & 1.00 & 1.00 & 1.00 & 1.00 \\
\hline & Group-II (3 mg I-1 of WS) & 1.00 & 1.00 & 1.00 & 1.00 \\
\hline Relative & Group-III (96hr-LC $\mathrm{C}_{50}$ of $\left.\mathrm{Cr}(\mathrm{VI})\right)$ & 2.12 & 4.40 & 5.16 & 5.34 \\
\hline Fold & Group-IV (96hr-LC $\mathrm{C}_{50}$ of $\mathrm{Cr}(\mathrm{VI})+1 \mathrm{mg} \mathrm{l}^{-1}$ of WS) & 1.96 & 4.00 & 4.72 & 5.00 \\
\hline \multirow[t]{2}{*}{ change } & Group-V (96 hr-LC $\mathrm{C}_{50}$ of $\mathrm{Cr}(\mathrm{VI})+2 \mathrm{mg} \mathrm{l}^{-1}$ of $\left.W S\right)$ & 1.54 & 3.64 & 4.40 & 4.48 \\
\hline & Group-VI (96 hr-LC ${ }_{50}$ of $\mathrm{Cr}(\mathrm{VI})+3 \mathrm{mg} \mathrm{l}^{-1}$ of WS) & 1.38 & 3.32 & 3.92 & 3.97 \\
\hline
\end{tabular}

somnifera@ $3 \mathrm{mg} \mathrm{l}^{-1}$. Environmental stressors are known to induce oxidative stress by over producing free radicals in fish and damaging cellular macromolecules-proteins, DNA etc. (Dwivedi et al., 2017; Pandey et al., 2011). A strong correlation between oxidative stress and impairment in cellular macromolecules like DNA, RNA, proteins etc. has also been reported by Chittezhath and Kuttan (2006). DNA damage or fragmentation involves double strand breaks (DSBs) leading to induction of MN (Xu et al., 2011). Further, induction of $M N$ in a cell reflects structural or numerical chromosomal aberrations appearing during mitosis (Heddle et al., 1991; Fenech et al., 2011). Aziz et al. (2012) also suggested genomic instability due to oxidative stress mediated DNA damage. A correlation between DNA damage and increased MN induction is amply reported in fishes (Matsumoto et al., 2006; Ratn et al., 2017; Yadav and Trivedi, 2009b). Thus, this can be inferred that $\mathrm{MN}$ assay can efficiently serve as an endpoint marker for assessment of genomic instability in fish and other aquatic organisms exposed to toxicants.

Plant metabolites are being increasingly used to safeguard aquatic biodiversity against contamination by noxious xenobiotics. Some plant products have enough potential to counteract genotoxic manifestations in animals after their exposure to genotoxicants. Moreover, they are eco-friendly and of medicinal importance and applied only for cure of mammalian models against physiological, environmental and ecotoxicological manifestations. Only a handful of information is available depicting application of plant based products for amelioration of genotoxicity/ genomic instability against a few remarkable toxicants in fishes. The plants amply used for the purpose in reference include, Azadirachta indica (neem) against pentachlorophenol and 2, 4-dichlorophenoxyacetic acid (2,4-D) (Farah et al., 2006); Lawsonia innermis ('henna') against copper sulphate (Kumar and Trivedi, 2015); Acacia catechu ('cutch') against arsenic tri-oxide (Dwivedi et al., 2015); Rauvolfia serpentine ('sarpgandha') against carbofuran (Tiwari et al., 2016); Curcuma longa (Turmeric powder) against chromium trioxide (Prasad et al., 2017); Melissa officinale (lemon balm) against arsenite (Dwivedi et al., 2017); Melissa officinalis (lemon balm) against Furadan 3G (Tiwari et al., 2017); Withania somnifera ('ashwagandha') against chromium tri-oxide (Prasad and Trivedi, 2018); Spirulina platensis against lead nitrate (Hamed et al., 2019); Curcuma longa (curcumin) against chromium tri-oxide (Awasthi et al., 2019). W. somnifera has gained therapeutic prominence and is widely used in Unani and Ayurvedic systems of medicine due to its ability to reduce reactive oxygen species, attune mitochondrial function, monitor apoptosis, reduce inflammation and boost endothelial function (Singh et al., 2011; Uddin et al., 2012). The ameliorative potential of $W$. somnifera against a variety of environmental stressors is well documented in non-piscean species (Alam et al., 2011). Withanolides and withaferin obtained from $W$. somnifera are promising therapeutic agents and are considered to possess anti-inflammatory, anti-arthritic and anti-oxidative properties by reducing lipid peroxidation in rats (Bhattacharya et al., 2001; Misra et al., 2008; Khan et al., 2015; Kushwaha, 2019). Panjamurthy et al. (2009) demonstrated the protective effect of Withaferin-A on 7, 12-dimethyl benz[a]anthracene (DMBA)induced micronucleus frequency in the bone marrow of golden Syrian hamsters by decreasing the frequency of micronucleus eventually to evade DNA damage. Several researches have been carried out to study the efficacy of plant-based metabolites to uncover their ameliorative potential against aquatic toxicants in fishes (Dwivedi et al., 2017, Awasthi et al., 2019).

The protective effects of $W$. somnifera against genotoxicity are probably due its strong reactive oxygen species scavenging ability that may have reduced the frequency of MN induction in fishes exposed to increasing concentrations of $W$. somnifera along with hexavalent chromium. This establishes its genoprotective role in C. punctatus. Priyandoko et al. (2011) opined that the cells treated with Withania somnifera could be protected against toxicity by multiple mechanisms, including subsequent damage at DNA and mitochondrial level, and induction of cellular defense machinery. In another study Mansour and Hafez (2012) also illustrated its protective role against radiation toxicity. Additionally, Sharma et al. (2011) documented the ameliorative effect of Withania somnifera on regulatory of lead nitrate induced nephrotoxicity in Swiss albino mice. Further, protective roles of Withania somnifera are mediated via its antioxidant activity (Bharavi et al., 2010; Rajasankar et al., 2009 and Udayakumar et al., 2010). The ameliorative effect of $W$. somnifera against hexavalent chromium was also observed in this study. $\mathrm{Cr}(\mathrm{VI})$ treatment significantly enhanced Micronuclei in blood cells however, there was a decline in micronuclei induction after treatment with root extract of $W$. somnifera in a close dependent 
manner. Therefore, it can be inferred that this decline in the frequency of $\mathrm{MN}$ induction with increasing concentrations of $W$. somnifera along with chromium trioxide ( $\left.96 \mathrm{hr}-\mathrm{LC}_{50} / 10,7.89 \mathrm{mgl}^{-1}\right)$ can be ascribed to genoprotective potential of this herb.

In the present study, a duration dependent increment in MN induction in erythrocytes of fish exposed to sub-lethal concentration of $\mathrm{Cr}(\mathrm{VI})$ in group III was observed. The frequency of micronuclei induction subsequently increased significantly $(p<$ 0.05 ) with the highest fold change of 5.34 after $96 \mathrm{hr}$ of exposure. Our findings are, thus, in concurrence with that of Awasthi et al. (2018) who also documented a significant $(p<0.05)$ increase in frequencies of $\mathrm{MN}$ induction in $\mathrm{C}$. punctatus exposed to $\mathrm{Cr}(\mathrm{VI})$ in a concentration and exposure dependent manner. However, findings of groups IV, V and VI wherein fishes were subjected to sub-lethal concentration $\left(96 \mathrm{hr}^{-\mathrm{LC}_{50}} / 10 ; 7.89 \mathrm{mg} \mathrm{l}^{-1}\right.$ ) of $\mathrm{Cr}(\mathrm{VI})$ along with 1,2 and $3 \mathrm{mg} \mathrm{I}^{-1}$ of $W$. somnifera root extract, respectively, indicate a significant $(p<0.05)$ ameliorative potential of $W$. somnifera in C. punctatus (Fig. 1). For all the three aforementioned groups, genomic instability registered a significant $(p<0.05)$ declining trend as evident by a gradual reduction in the frequency of micronuclei induction with corresponding fold changes in a decreasing order: $1.96>1.54$ $>1.38$ in comparison to group III (2.12) with respect to control, after $24 \mathrm{hr}$ of exposure. Similar declining trend in induction of MN frequency in terms of fold changes were also obtained for 48,72 and $96 \mathrm{hr}$ of exposure. These are $4.00>3.64>3.32$ after $48 \mathrm{hr}$ of exposure period, in comparison to group III (4.40) with respect to control; $4.72>4.40>3.92$ after $72 \mathrm{hr}$ of exposure with respect to Group-III (5.16) when compared to the control and $5.00>4.48>$ 3.97 after $96 \mathrm{hr}$ of exposure, in comparison to group III (5.34), with respect to control, respectively in groups IV, V, and $\mathrm{VI}$ (Table 1). Laboratory microcosm based studies involving preliminary biological screening of plants and their metabolites with promising therapeutic potential finds ample scope in substantially counteracting several environmental toxicants. Besides, their role as geno-protective and ameliorative agents against anomalies induced by waterborne toxicants, after proper standardization, they can be successfully applied as dietary inclusions, based on nutrigenomic approach, for aquaculture activities in water bodies contaminated with metals like hexavalent chromium.

\section{Acknowledgments}

The authors feel grateful to the Head, Department of Zoology, University of Lucknow, Lucknow-226007 for providing necessary laboratory facilities and encouragement throughout the studies. One of the authors, Mr. Rajesh Prasad, an UGCBSR-fellow (FileNo.F.25-1/2013- 2014(BSR)/7-109/2007/BSR) is thankful to the University Grants Commission (UGC), New Delhi, India for providing financial assistance in the form of fellowship. We sincerely acknowledge the UGC for Special Assistance Program (SAP) and Department of Science and Technology, Government of India for providing FIST and PURSE Programs.

\section{References}

Ahmad, M.K., A.A. Mahdi, K.K. Shukla, N. Islam, S. Rajender, D. Madhukar, S.N. Shankhwar and S. Ahmad: Withania somnifera improves semen quality by regulating reproductive hormone levels and oxidative stress in seminal plasma of infertile males. Fertil. Steril., 94, 989-996 (2010).

Alam, N., M. Hossain, I. Khalil, M. Moniruzzaman, S.A. Sulaiman and S.H. Gan: High catechin concentrations detected in Withania somnifera (Ashwagandha) by high performance liquid chromatography analysis. BMC Comple. Altern. Medi., 11, 1-8 (2011).

Andersen, J.K.: Oxidative stress in neurodegeneration: Cause or consequence? Nat. Med., 10, S18-S25 (2004).

APHA: Standard Methods for the Examination of Water and Wastewater. $22^{\text {nd }}$ Edn., APHA, AWWA), WPCF, Washington DC, USA (2012).

ATSDR: Agency for Toxic Substances and Disease Registry (2017). https://www.atsdr.cdc.gov/spl/index.html

Atta-ur-rahman, S.A. Jamal, M.I. Choudhary and E. Asif: Two withanolides from Withania somnifera. Phytochemistry, 30, 3824-3826 (1991).

Awasthi, Y., A. Ratn, R. Prasad, M. Kumar, A. Trivedi, J.P. Shukla and S.P. Trivedi: A protective study of curcumin associated with $\mathrm{Cr}^{6+}$ induced oxidative stress, genetic damage, transcription of genes related to apoptosis and histopathology of fish, Channa punctatus (Bloch, 1793). Environ. Toxicol. Pharmacol., 71, 103-109 (2019).

Awasthi, Y., A. Ratn, R. Prasad, M. Kumar and S.P. Trivedi: An in-vivo analysis of $\mathrm{Cr}^{6+}$ induced biochemical, genotoxicological and transcriptional profiling of genes related to oxidative stress, DNA damage and apoptosis in liver of fish, Channa punctatus (Bloch, 1793). Aquat. Toxicol., 200, 158-167 (2018).

Aziz, K., S. Nowsheen, G. Pantelias, G. lliakis, V.G. Gorgoulis and A.G. Georgakilas: Targeting DNA damage and repair: Embracing the pharmacological era for successful cancer therapy. Pharmacol. Ther., 133, 334-350 (2012).

Bandyopadhyay, M., S. Jha and D. Tepfer: Changes in morphological phenotypes and withanolide composition of Ri-transformed roots of Withania somnifera. Plant Cell Rep., 26, 599-609 (2007).

Banerjee, S., S.R. Joshi, T. Mandal and G. Halder: Insight into $\mathrm{Cr}^{6+}$ reduction efficiency of Rhodococcus erythropolis isolated from coalmine waste water. Chemosphere, 167, 269-281 (2017).

Bharavi, K., A.G. Reddy, G.S. Rao, A.R. Reddy and S.V.R. Rao: Reversal of cadmium-induced oxidative stress in chicken by herbal adaptogens, Withania somnifera and Ocimum sanctum. Toxicol. Int., 17, 59-63 (2010).

Bhattacharya, A., S. Ghosal and S.K. Bhattacharya:Anti-oxidant effect of Withania somnifera glycowithanolides in chronic footshock stressinduced perturbations of oxidative free radical scavenging enzymes and lipid peroxidation in rat frontal cortex and striatum. $J$. Ethnopharmacol., 74, 1-6 (2001).

Bolognesi, C. and M. Hayashi: Micronucleus assay in aquatic animals. Mutagenesis, 26, 205-213 (2011).

Chittezhath, M. and G. Kuttan: Radioprotective activity of naturally occurring organosulfur compounds. Tumori, 92, 163-169 (2006).

Datta, A.K., A. Das, A. Bhattacharya, S. Mukherjee, Benoy and K. Ghosh: Medicinal and aromatic plant science and biotechnology an overview on Withania somnifera (L.) dunal- the "Indian ginseng." Med. Aromat. Plant Sci. Biotechnol., 5, 1-15 (2011).

Dwivedi, S., V. Tiwari and S.P. Trivedi: Arsenite induced genotoxic effect and its phytoremediation by Acacia catechu leaf extract in freshwater fish, Channa punctatus (Bloch). Int. J. Fish. Aquat. Stud., 2, 163-165(2015).

Dwivedi, S., M. Kumar and S.P. Trivedi: Mitigating potential of Melissa 
officinale against As3+-induced cytotoxicity and transcriptional alterations of $\mathrm{Hsp} 70$ and Hsp27 in fish, Channa punctatus (Bloch). Environ. Monit. Assess., 189, 306 (2017).

Farah, M.A., B. Ateeq and W. Ahmad: Antimutagenic effect of neem leaves extract in freshwater fish, Channa punctatus evaluated by cytogenetic tests. Sci. Total Environ., 364, 200-214 (2006).

Fenech, M.: The in-vitro micronucleus technique. Mutat. Res., 455, 81-95 (2000).

Fendorf, S.E.: Surface reactions of chromium in soils and waters. Geoderma, 67, 55-71(1995).

Fenech, M.: Cytokinesis-block micronucleus cytome assay. Nat Protoc., 2, 1084-1104 (2007).

Fenech, M., M. Kirsch-Volders, A.T. Natarajan, J. Surralles, J.W. Crott, J. Parry, H. Norppa, D.A. Eastmond, J.D. Tucker and P. Thomas: Molecular mechanisms of micronucleus, nucleoplasmic bridge and nuclear bud formation in mammalian and human cells. Mutagen., 26, 125-132 (2011).

Feng, M., H. Yin, H. Peng, Z. Liu, G. Lu and Z. Dang: Hexavalent chromium induced oxidative stress and apoptosis in Pycnoporus sanguineus. Environ. Pollut., 228, 128-139 (2017).

Ghani, A.: Effect of chromium toxicity on growth, chlorophyll and some mineral nutrients of Brassica juncea (L.) Egypt. Acad. J. Biol. Sci. H. Bot., 2, 9-15(2011).

Gu, Y., W. Xu, Y. Liu, G. Zeng, J. Huang, X. Tan, H. Jian, X. Hu, F. Li and D. Wang: Mechanism of $\mathrm{Cr}(\mathrm{VI})$ reduction by Aspergillus niger: Enzymatic characteristic, oxidative stress response, and reduction product. Environ. Sci. Pollut. Res., 22, 6271-6279 (2015).

Gürkan, R., H.I. Ulusoy and M. Akçay: Simultaneous determination of dissolved inorganic chromium species in wastewater/natural waters by surfactant sensitized catalytic kinetic spectrophotometry. Arab. J. Chem., 10, S450-460 (2017).

Haigis, M.C. and B.A.Yankner: The aging stress response. Mol. Cell, 40, 333-344 (2010).

Hamed, M., H.A.M. Soliman and A.E.D.H. Sayed: Ameliorative effect of Spirulina platensis against lead nitrate-induced cytotoxicity and genotoxicity in catfish, Clarias gariepinus. Environ. Sci. Pollut. Res., 26, 20610-20618 (2019).

Hanaa, M., S., E.A. Eweida and A. Farag: Heavy metals in drinking water and their environmental impact on human health. ICHEM, 1, $542-556(2000)$.

Heddle, J.A., M.C. Cimino, M. Hayashi, F. Romagna, M.D. Shelby, J.D. Tucker, P. Vanparys and J.T. MacGregor: Micronuclei as an index of cytogenetic damage: Past, present, and future. Environ. Mol. Mutagen., 18, 277-291 (1991).

Hosny, H. Mansour and H. Farouk Hafez: Protective effect of Withania somnifera against radiation-induced hepatotoxicity in rats. Ecotoxicol. Environ. Saf., 80, 14-19 (2012).

Hutchinson, T.H., C. Bögi, M.J. Winter and J.W. Owen: Benefits of the maximum tolerated dose (MTD) and maximum tolerated concentration (MTC) concept in aquatic toxicology. Aquat. Toxicol., 91, 197-202 (2009).

Kapoor, L.D.: Handbook of Ayurvedic Medicinal Plants. CRC Press (2001).

Khan, M.A., M. Subramaneyaan, V.K. Arora, B.D. Banerjee and R.S. Ahmed: Effect of Withania somnifera (Ashwagandha) root extract on amelioration of oxidative stress and autoantibodies production in collagen-induced arthritic rats. J. Complement. Integr. Med., 12, 117-125 (2015).

Kirsch-Volders, M., G. Plas, A. Elhajouji, M. Lukamowicz, L. Gonzalez, K. Vande Loock and I. Decordier: The in-vitro MN assay in 2011: Origin and fate, biological significance, protocols, high throughput methodologies and toxicological relevance. Arch. Toxicol., 85, 873-899 (2011).
Koleli, N. and A. Demir: Chromite. In: Environmental Materials and Waste. Elsevier, Academic Press, pp. 245-263 (2016).

Kumar, M., N. Gupta, A. Ratn, Y. Awasthi, R. Prasad, A. Trivedi and S.P. Trivedi: Biomonitoring of heavy metals in river Ganga water, sediments, plant, and fishes of different trophic levels. Biol. Trace Elem. Res. (2019). doi: 10.1007/s12011-019-01736-0

Kumar, V. and S. P. Trivedi : Antimutagenic effect of Lawsonia inermis leaves extract against copper toxicity in a fresh water fish, Channa punctatus (Bloch.). Proc. Zool. Soc. India, 14, 123-128 (2015).

Kushwaha, V.: Nephroprotection of Withania somnifea root extract against gentamicin induced nephrotoxicity: A histological evaluation in experimental Wistar rats. Int. J. Basic Clin. Pharmacol., 8, 2297-2303 (2019).

Laingam, S., S.M. Froscio and A.R. Humpage: Flow-cytometric analysis of in-vitro micronucleus formation: Comparative studies with WIL2-NS human lymphoblastoid and L5178Y mouse lymphoma cell lines. Mutat. Res., 656, 19-26 (2008).

Matsumoto, S.T., M.S. Mantovani, M.I.A. Malaguttii, A.L. Dias and I.C. Fonseca and M.A. Marin-Morales: Genotoxicity and mutagenicity of water contaminated with tannery effluents, as evaluated by the micronucleus test and comet assay using the fish, Oreochromis niloticus and chromosome aberrations in onion root-tips. Genet. Mol. Biol., 29, 148-158(2006).

Mirjalili, M.H., E. Moyano, M. Bonfill, R.M. Cusido and J. Palazón: Steroidal lactones from Withania somnifera, an ancient plant for novel medicine. Molecules, 14, 2373-2393 (2009).

Misra, L., P. Mishra, A. Pandey, R.S. Sangwan, N.S. Sangwan and R. Tuli: Withanolides from Withania somnifera roots. Phytochemistry, 69, 1000-1004 (2008).

Mohanty, M. and H.K. Patra: Effect of ionic and chelate assisted hexavalent chromium on mung bean seedlings (Vigna radiata $\mathrm{L}$. wilczek. var k-851) during seedling growth. J. Stress Physio. Biochem., 9, 232-241 (2013).

Ohtake, H. and S. Silver: Biological degradation and bioremediation of toxic chemicals. Chapman \& Hall, Portland (1994).

Pandey, A.K., N.S. Nagpure, S.P. Trivedi, R. Kumar and B. Kushwaha: Profenofos induced DNA damage in freshwater fish, Channa punctatus (Bloch) using alkaline single cell gel electrophoresis. Mutat. Res., 726, 209-214(2011).

Panjamurthy, K., S. Manoharan, S. Balakrishnan, K. Suresh, M. Nirmal, N. Senthil and L. Alias: Protective effect of Withaferin-A on micronucleus frequency and detoxication agent during experimental oral carcinogenesis. African J. Tradit. Complement. Altern. Med., 6, 1-8 (2009).

Paravicini, T. and R. Touyz: Redox signaling in hypertension. Cardiovasc. Res., 71, 247-258 (2006).

Prasad, R., M. Kumar and S. P. Trivedi: Antigenotoxic effect of turmeric powder extract curcumin against chromium trioxide induced genotoxicity in fish Channa punctatus. J. Entomol. Zool. Stud., 5, 89-94 (2017).

Prasad, R. and S.P. Trivedi: Ameliorative potential of Withania somnifera ('Ashwagandha') against water borne hexavalent chromium induced genotoxicity in a fish, Channa punctatus (Bloch, 1793): A study based on chromosomal aberrations. Res. Environ. Life Sci., 11, 122-129 (2018).

Priyandoko, D., T. Ishii, S.C. Kaul and R. Wadhwa: Ashwagandha leaf derived withanone protects normal human cells against the toxicity of methoxyacetic acid, a major industrial metabolite. PLOS ONE, 6, e19552 (2011).

Rajasankar, S., T. Manivasagam and S. Surendran: Ashwagandha leaf extract: A potential agent in treating oxidative damage and physiological abnormalities seen in a mouse model of Parkinson's disease. Neurosci. Lett., 454, 11-15(2009). 
Ratn, A., Y. Awasthi, M. Kumar, S.K. Singh, R. Tripathi and S.P. Trivedi: Phorate induced oxidative stress, DNA damage and differential expression of $\mathrm{p} 53$, apaf- 1 and cat genes in fish, Channa punctatus (Bloch, 1793). Chemosphere, 182, 382-391 (2017).

Schmid, W.: The micronucleus test. Mutat. Res., 31, 9-15(1975).

Sharma, V., S. Sharma, Pracheta, R. Paliwal and S. Sharma: Therapeutic efficacy of Withania somnifera root extract in the regulation of lead nitrate induced nephrotoxicity in Swiss albino mice. J. Pharm. Res., 4, 755-758 (2011).

Sevgiler, Y., S. Karaytug and F. Karayakar: Antioxidative effects of Nacetylcysteine, lipoic acid, taurine, and curcumin in the muscle of Cyprinus carpio (L.) exposed to cadmium. Arch. Ind. Hyg. Toxicol., 62, 1-9 (2011).

Shukla, V., S.K. Mishra and H.C. Pant: Oxidative stress in neurodegeneration. Adv. Pharmacol. Sci., Volume .2011, Article ID 572634, 13 pages (2011).

Singh, N., M. Bhalla, P. de Jager and M. Gilca: An overview on Ashwagandha: Arasayana (rejuvenator) of ayurveda. Afr. J. Tradit. Complement. Altern. Med., 8, 208-213 (2011).

Stohs, S.J. and D. Bagchi: Oxidative mechanisms in the toxicity of metal ions. Free Radic. Biol. Med., 18, 321-336 (1995).

Tiwari, V., M. Kumar and S.P. Trivedi: Protective effects of perennial herb, Melissa officinalis against furadan 3G induced cytotoxicity in Channa punctatus. J. Environ. Biol., 38, 1375-1381 (2017).

Tiwari, V., M. Kumar and S.P. Trivedi: Amelioration by Sarpagandha root extract to counter DNA damage induced by carbofuran in fish using RAPD tool. J. Env. Bio-Sci., 30, 87-93 (2016).

Tiwari, V. and S.P. Trivedi: Investigations on remedial role of a Rauwolfia serpentine root extract against carbofuran formulation induced genotoxicity in Channa punctatus. J. Environ. Biol., 40, 1023-1028 (2019)
Trachootham, D., J. Alexandre and P. Huang: Targeting cancer cells by ROS-mediated mechanisms: A radical therapeutic approach? Nat. Rev. Drug. Discov., 8, 579-591 (2009).

Udayakumar, R., S. Kasthurirengan, A. Vasudevan, T.S. Mariashibu, J.J.S. Rayan, C.W. Choi, A. Ganapathi and S.C. Kim: Antioxidant effect of dietary supplement Withania somnifera (L.) reduce blood glucose levels in alloxan-induced diabetic rats. Plant Foods Hum. Nutr., 65, 91-98 (2010)

Uddin, Q., L. Samiulla, V.K. Singh and S.S. Jamil: Phytochemical and pharmacological profile of Withania somnifera Dunal: A review. J. Appl. Pharm. Sci., 02, 170-175 (2012).

U.S. Environmental Protection Agency: Drinking Water Standards and Health Advisories Tables (EPA 822-F-18-001) (2018).

World Health Organization: Guidelines for Drinking-Water Quality, $3^{\text {rd }}$ Edn., Geneva (2008). https://www.who.int/water_sanitation_health/ dwq/fulltext.pdf.

Wolińska, A., Z. Stępniewska and R. Włosek: The influence of old leather tannery district on chromium contamination of soils. Water and Plants, 5, 253-258 (2013).

Xu, B., Z. Sun, Z. Liu, H. Guo, Q. Liu, H. Jiang, Y. Zou, Y. Gong, J.A Tischfield and C. Shao: Replication stress induces micronuclei comprising of aggregated DNA double-strand breaks. PLOS ONE, 6, e18618(2011).

Yadav, K.K. and S.P. Trivedi: Chromosomal aberrations in a fish, Channa punctata after in-vivo exposure to three heavy metals. Mutat. Res., 678, 7-12 (2009a).

Yadav, K.K. and S.P. Trivedi: Sublethal exposure of heavy metals induces micronuclei in fish, Channa punctata. Chemosphere, 77 , 1495-1500 (2009b).

Zayed, A.M. and N. Terry: Chromium in the environment: Factors affecting biological remediation. Plant Soil, 249, 139-156 (2003). 